Acta technologica agriculturae 3

Nitra, Slovaca Universitas Agriculturae Nitriae, 2013, p. 63-66

\title{
EFFECT OF TEMPERATURE AND USED INGREDIENTS ON RHEOLOGICAL PARAMETERS OF PANCAKE DOUGH
}

\author{
Peter HLAVÁČ, Monika BOŽIKOVÁ
}

Slovak University of Agriculture in Nitra, Slovakia

\begin{abstract}
This paper presents the selected rheological properties of pancake dough such as dynamic and kinematic viscosity and fluidity. The effect of used ingredients and temperature on rheological properties is investigated. Measurements were performed on three pancake dough samples. In two samples, there was used milk with a different fat content, and in the third sample, all ingredients were in a powder state. A digital rotational viscometer Anton Paar DV-3P was used for measuring the rheological properties. The principle of viscometer measurement is based on the dependence of sample resistance to probe rotation. Results of measurements are shown as graphical dependencies of rheological parameters on temperature. Exponential functions were used to express the dependencies of all rheological parameters on temperature. Dynamic and kinematic viscosity decreased, and fluidity increased with temperature. The highest values of dynamic viscosity were obtained for pancake dough from powder ingredients. A higher fat content of used milk caused higher values of dynamic viscosity.
\end{abstract}

Keywords: pancake dough, temperature, used ingredients, dynamic and kinematic viscosity, fluidity

The identification of food materials physical properties is necessary for quality evaluation. During the processing of food materials, we need to check their status step by step, in different parts of processing. For detection of food material status, we could analyse chemical and physical properties. Chemical analyses usually take longer time intervals than the study of physical properties. A modern physical research often uses dynamic methods of measurements, which are quicker than static methods. By using dynamic methods, we can obtain the characteristics of material in a short time. This fact is very important for practice.

This article deals with rheological properties, which are very complex characteristics of materials. It presents the selected theoretical basics from rheology and rheological measurement method. Results are presented as temperature relations of dynamic and kinematic viscosity and fluidity in a temperature range of $12-26^{\circ} \mathrm{C}$ in Figs $1-6$. The coefficients of regression equations and coefficients of determination are summarized in Tab. 1 and Tab. 2.

Dough is usually made from flour (or combination of flours), liquid components (water or milk or other dairy products), optionally eggs, fat ingredients (vegetable oils or animal fats), sweeteners (natural or artificial, liquid or dry) and additional flavourings (salt, whey, malt, yeasts, vanilla, etc.) (Domingues and Kirk, 2003). Properties of dough were examined by many authors. Physicochemical properties of gluten-free pancakes made from rice and sweet potato flours were compared by Shih et al. (2006). The effect of composition on dough was examined by Koksel and Scanlon (2012). Chin et al. (2005) made an investigation of bread doughs with different densities, salt contents and water levels. The effect of nonpolar lipids physical state on gluten-starch and wheat flour dough rheology and microstructure were measured by Watanabe et al. (2002). Rheological properties of dough made of starch and gluten from several cereal sources were analysed by Petrofsky and Hoseney (1995). The rheological behaviour of wheat gluten and starch doughs were investigated by Yang et al. (2011).

Viscosity as one of the most important rheological parameters is defined as the resistance of fluid to flow. The unit of dynamic viscosity in SI units is Pa.s. Viscosity changes with temperature. The difference in the effect of temperature on the viscosity of fluids and gases is related to the difference in their molecular structure. The viscosity of the most of liquids decreases with increasing temperature. Theories have been proposed regarding the effect of temperature on the viscosity of liquids. According to Eyering theory, molecules of liquids continuously move into vacancies (Bird et al., 1960).

This process permits flow but requires energy. Activation energy is more readily audible at higher temperatures, and the fluid flows easily. The temperature effect on viscosity can be described by an Arrhenius-type equation

$$
\eta=\eta_{0} e^{-\frac{E_{A}}{R T}}
$$

where:

$$
\begin{aligned}
& \eta_{0}-\text { a reference value of dynamic viscosity } \\
& E_{A}-\text { activation energy } \\
& R \quad-\text { gas constant and } T \text { is absolute temperature (Figura } \\
& \quad \text { and Teixeira, 2007) }
\end{aligned}
$$

Liquid molecules are closely spaced with strong cohesive forces between them. The temperature dependence of viscosity can also be explained by cohesive forces between molecules (Munson et al., 1994). As temperature increases, these cohesive forces between molecules decrease and flow becomes freer. As a result, viscosities of liquids decrease as temperature increases. In liquids, intermolecular (cohesive) forces play an important role. Viscosities of liquids show little dependence on density, molecular velocity or mean free path. In most liquids, viscosity is constant up to a pressure of $10.134 \mathrm{MPa}$, but at higher pressures, viscosity increases as pressure increases (Sahin and Sumnu, 2006). 
Kinematic viscosity $v$ is defined as a ratio between dynamic viscosity $\eta$ and the density of fluid $\rho$ at the same temperature:

$$
v=\frac{\eta}{\rho}
$$

Its unit in $\mathrm{SI}$ units is $\mathrm{m}^{2} \cdot \mathrm{s}^{-1}$. The reciprocal value of dynamic viscosity $\eta$ is called fluidity $\varphi$ and the physical unit of fluidity is $\mathrm{Pa}^{-1} \cdot \mathrm{s}^{-1}$ :

$$
\varphi=\frac{1}{\eta}
$$

In our measurements, we have compared three types of pancake doughs. The composition of dough no. 1 and dough no. 2 was approximately the same. The used ingredients were 2 eggs, $100 \mathrm{~g}$ of wheat flour, $250 \mathrm{ml}$ of milk, two spoons of sunflower oil and salt. The only difference was in the milk used. In dough no. 1, there was used the milk with a $1.5 \%$ fat content and in dough no. 2 the milk with a $3.5 \%$ fat content. Dough no. 3 was prepared from powder ingredients (wheat flour, powdered milk, powdered eggs and sugar) and mixed with $480 \mathrm{ml}$ of water.

The ingredients of all the three pancake doughs were properly mixed and left for relaxation for $15 \mathrm{~min}$. All the three samples were mixed after relaxation as well. Then, the samples were cooled down to temperature $10{ }^{\circ} \mathrm{C}$, and dynamic viscosity was measured at eight temperatures in a range of $12{ }^{\circ} \mathrm{C}-26^{\circ} \mathrm{C}$.

The measuring of dynamic viscosity was performed using the digital viscometer Anton Paar (DV-3P). The principle of measuring by this viscometer is based on the dependence of sample resistance to probe rotation. The probe with signification R7 was used in our measurements. The frequency of probe rotation was $200 \mathrm{~min}^{-1}$.

Temperature dependencies of dynamic and kinematic viscosity can be described by decreasing exponential functions $(4,5)$ or by the power function of third degree $(7,8)$. In case of temperature dependencies of fluidity, increasing exponential functions (6) or the power function of third degree (9) can be used.

$$
\begin{gathered}
\eta=A e^{-B\left(\frac{t}{t_{0}}\right)} \\
v=C e^{-D\left(\frac{t}{t_{0}}\right)} \\
\varphi=E e^{F\left(\frac{t}{t_{0}}\right)} \\
\eta=-G\left(\frac{t}{t_{0}}\right)^{3}+H\left(\frac{t}{t_{0}}\right)^{2}-I\left(\frac{t}{t_{0}}\right)+J \\
v=-K\left(\frac{t}{t_{0}}\right)^{3}+K\left(\frac{t}{t_{0}}\right)^{2}-M\left(\frac{t}{t_{0}}\right)+N \\
\varphi=P\left(\frac{t}{t_{0}}\right)^{3}-Q\left(\frac{t}{t_{0}}\right)^{2}+S\left(\frac{t}{t_{0}}\right)-T
\end{gathered}
$$

where:

$$
t \quad \text { - temperature }
$$$$
t_{0}-1{ }^{\circ} \mathrm{C}
$$

$\stackrel{\circ}{A} B, C, D, E, F, G, H, I, J, K, L, M, N, P, Q, S, T$ - are constants dependent on the kind of material and on ways of processing and storing

\section{Results and discussion}

The temperature dependencies of dynamic viscosity for all pancake doughs are shown in Fig. 1 and 2.

It is possible to observe from Fig. 1 and Fig. 2 that the dynamic viscosity of pancake doughs is decreasing with increasing of temperature. The progress can be described by a decreasing exponential function, which is in accordance with Arrhenius equation (1). The regression coefficients and coefficients of determination are shown in Tab. 1 and Tab. 2. It can be seen from Fig. 1 that the dynamic viscosity of dough no. 2 is higher than the viscosity of dough no. 1. This proportion is caused by a different fat content in the milk used in doughs. The used ingredients had caused that the dough no. 3 had the highest viscosity.

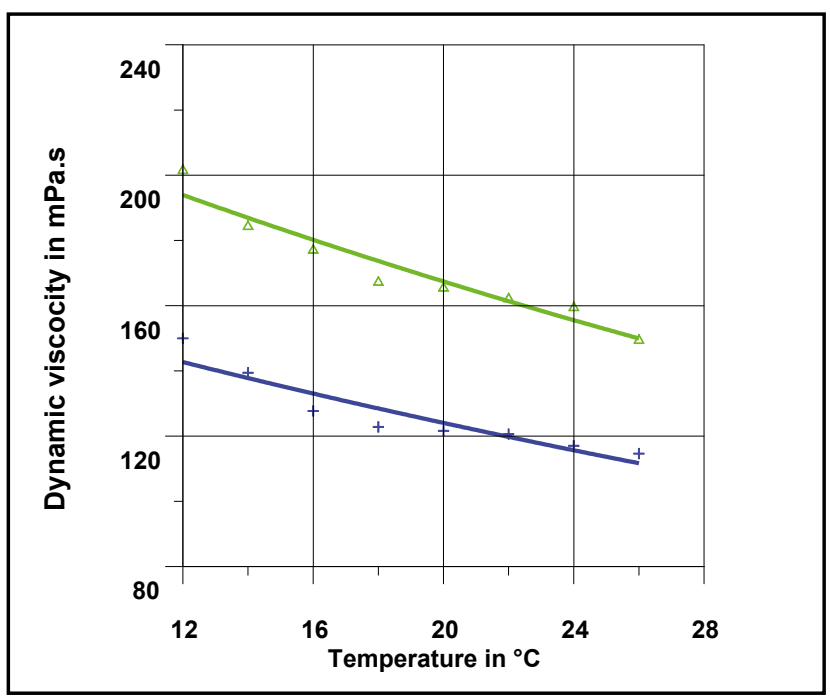

Figure 1 Temperature dependencies of dynamic viscosity for the sample dough no. $1(+)$ and dough no. $2(\triangle)$

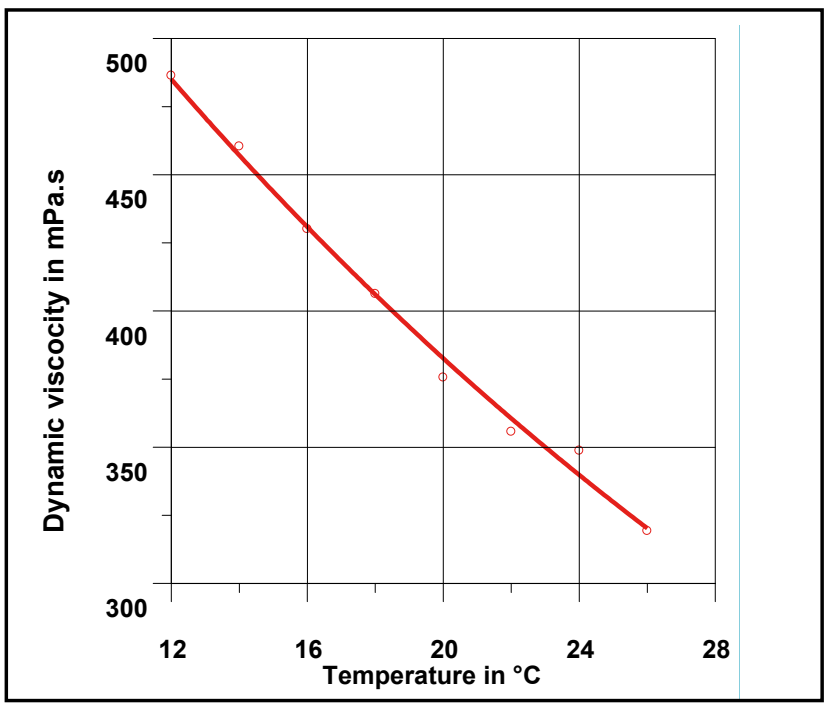

Figure 2 Temperature dependency of dynamic viscosity for the sample dough no. $3(\bigcirc)$ 


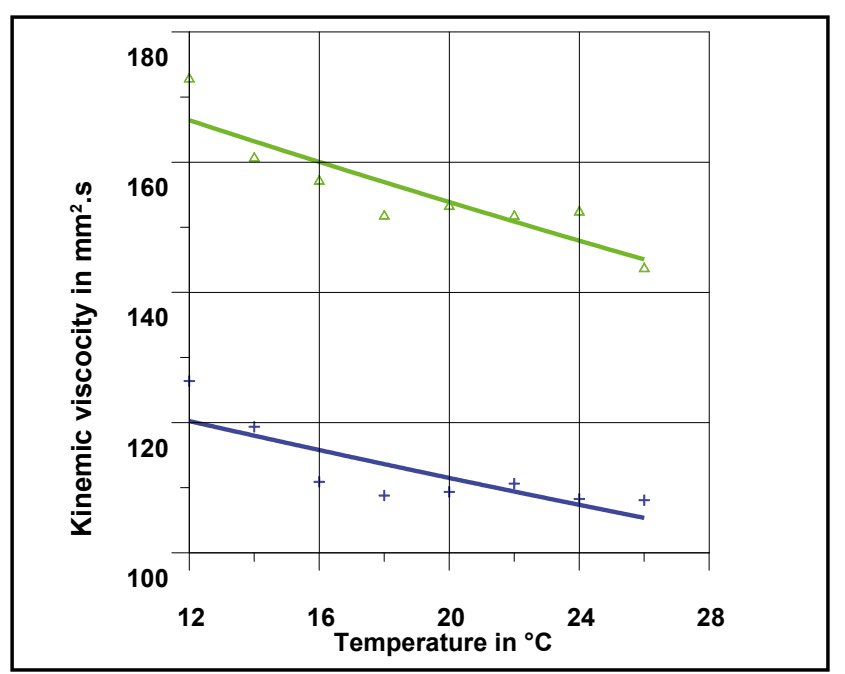

Figure 3 Temperature dependencies of kinematic viscosity for the sample dough no. $1(+)$ and dough no. $2(\triangle)$

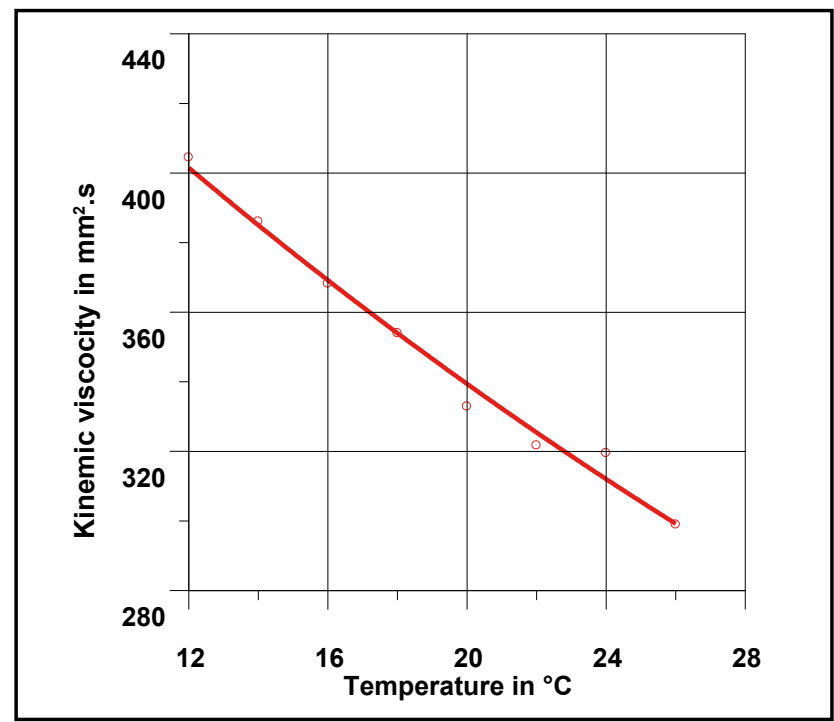

Figure 4 Temperature dependency of kinematic viscosity for the sample dough no. $3(O)$

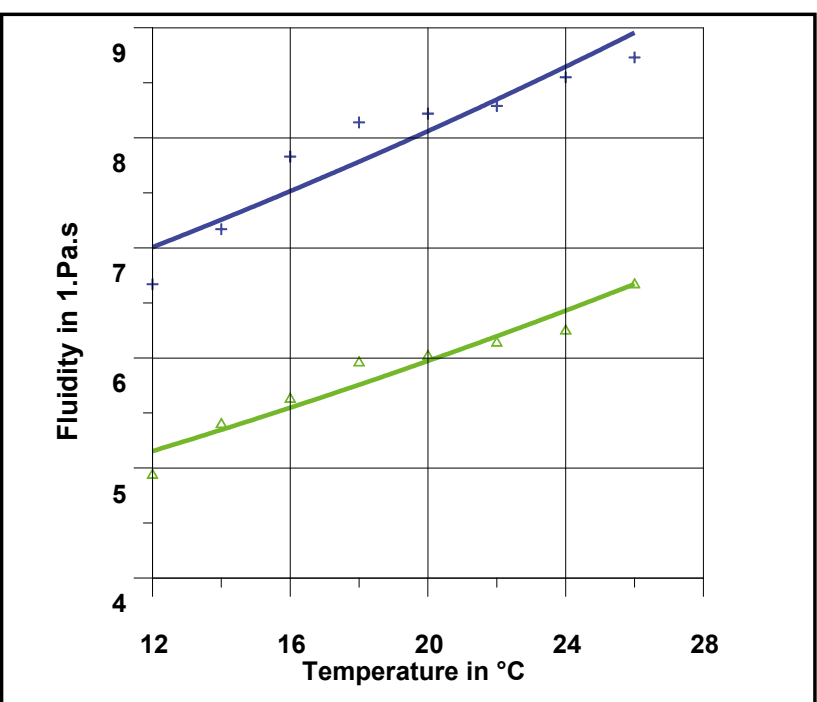

Figure 5 Temperature dependencies of fluidity for the sample dough no. $1(+)$ and dough no. $2(\triangle)$

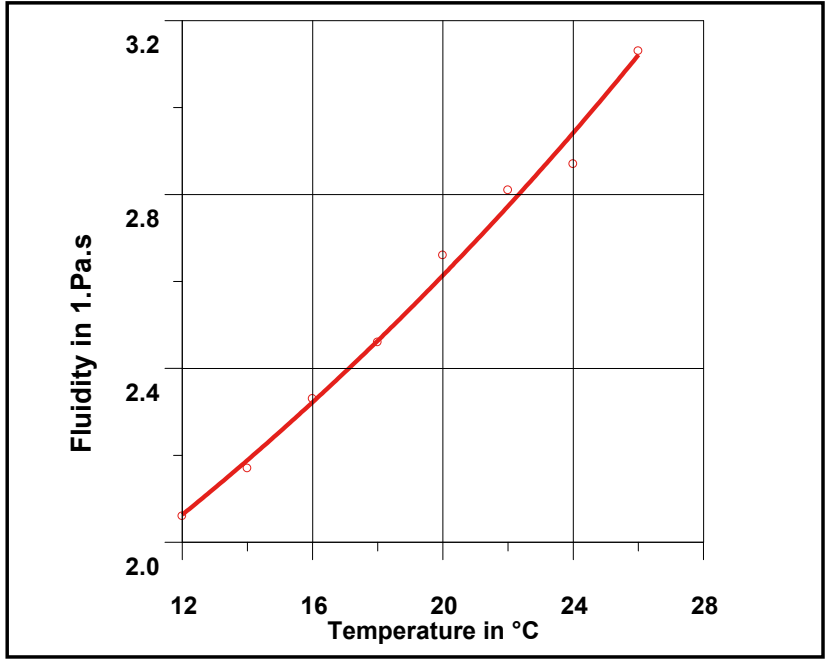

Figure 6 Temperature dependency of fluidity for the sample dough no. $3(\mathrm{O})$

Fig. 3 and Fig. 4 show the temperature dependencies of kinematic viscosity for the measured samples. Dependencies of kinematic viscosity on temperature can also be described by a decreasing function for all the samples of dough. The regression coefficients and coefficients of determination are shown in Tab. 1 and Tab. 2.

The temperature dependencies of fluidity can be seen in Fig. 5 and Fig. 6. It is evident that fluidity increases with increasing of temperature. The regression coefficients and coefficients of determination are shown in Tab. 1 and Tab. 2. The proportion of curves in Figs 3-6 can be explained in the same way as for the previous Fig. 1 and Fig. 2 .

It can be seen in Tab. 1 that the highest coefficients of determination in all measurements are for the sample dough no. 3. In all measurements, lower coefficients of determination are for the dough no. 1 and dough no. 2. It can be concluded that exponential functions could be used for the dough no. 3 only. A different function must be used

Table 1 Coefficients $A, B, C, D, E, F$ of regression equations $(4,5$ and 6$)$ and coefficients of determination $\left(R^{2}\right)$

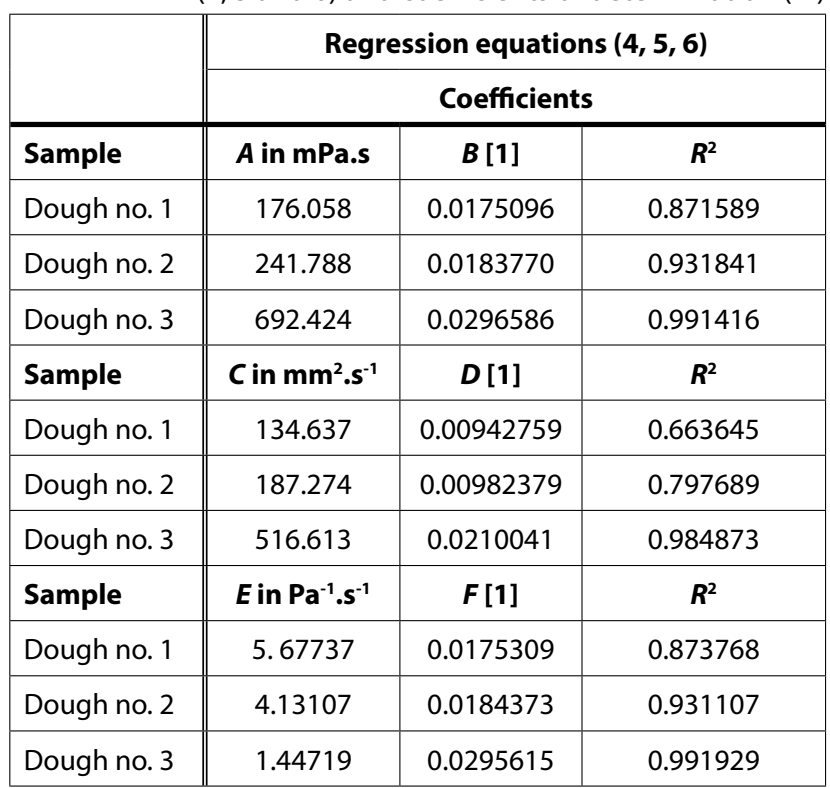


Table 1

Coefficients $G, H, I, J, K, L, M, N, P, Q, S, T$ of regression equations (7, 8 and 9) and coefficients of determination $\left(R^{2}\right)$

\begin{tabular}{|c|c|c|c|c|c|}
\hline \multirow[b]{3}{*}{ Sample } & \multicolumn{5}{|c|}{ Regression equations $(7,8,9)$} \\
\hline & \multicolumn{5}{|c|}{ Coefficients } \\
\hline & $G$ in $\mathrm{mPa} . \mathrm{s}$ & $H$ in $\mathrm{mPa} . \mathrm{s}$ & I in mPa.s & $J$ in $\mathrm{mPa} . \mathrm{s}$ & $R^{2}$ \\
\hline Dough no. 1 & 0.0260417 & 1.69524 & 37.5280 & 401.955 & 0.991358 \\
\hline Dough no. 2 & 0.0411932 & 2.52614 & 53.0455 & 545.920 & 0.994150 \\
\hline Sample & $K$ in $\mathrm{mm}^{2} . \mathrm{s}^{-1}$ & $L$ in $\mathrm{mm}^{2} . \mathrm{s}^{-1}$ & $M$ in $\mathrm{mm}^{2} . \mathrm{s}^{-1}$ & $N$ in $\mathrm{mm}^{2} \cdot \mathrm{s}^{-1}$ & $R^{2}$ \\
\hline Dough no. 1 & 0.0228756 & 1.47265 & 31.4332 & 331.686 & 0.971237 \\
\hline Dough no. 2 & 0.0407955 & 2.43998 & 48.5765 & 475.114 & 0.979007 \\
\hline Sample & $P$ in $\mathrm{Pa}^{-1} \cdot \mathrm{s}^{-1}$ & $Q$ in $\mathrm{Pa}^{-1} \cdot \mathrm{s}^{-1}$ & $S$ in $\mathrm{Pa}^{-1} \cdot \mathrm{s}^{-1}$ & $T$ in $\mathrm{Pa}^{-1} \cdot \mathrm{s}^{-1}$ & $\mathbf{R}^{2}$ \\
\hline Dough no. 1 & 0.00128156 & 0.0829301 & 1.85159 & 5.87515 & 0.988286 \\
\hline Dough no. 2 & 0.00129735 & 0.0773565 & 1.59336 & 5.28891 & 0.991179 \\
\hline
\end{tabular}

for the dough no. 1 and dough no. 2, i.e. the power function of third degree in this case. The regression coefficients and coefficients of determination are shown in Tab. 2.

\section{Conclusion}

Automatically controlled processes in manufacturing, handling and holding require exact knowledge about physical quantities of materials. For quality evaluation of food materials, it is necessary to know their physical parameters, for example rheological properties (Božiková and Hlaváč, 2010). Rheological properties were measured by many authors. The flow behaviour of pancake slurry is important in pancake preparation. Batter viscosity affects the appearance, texture and sensory quality of finished products (Shih et al., 2005).

The temperature dependencies of all pancake doughs dynamic and kinematic viscosity had a decreasing shape, and the temperature dependencies of fluidity had an increasing shape (Figs 1-6). Exponential functions (Tab. 1) were used for the temperature dependencies of dough no. 3 rheological properties, which is in accordance with Arrhenius equation (1). We found that for the dough no. 1 and dough no. 2, there must be used a different function, in this case, the power function of third degree (Tab. 2). It can be seen from Fig. 1 that the dynamic viscosity of dough no. 2 is higher than the viscosity of dough no. 1. This proportion is caused by a different fat content in the milk used in doughs. The used ingredients caused that the dough no. 3 had the highest viscosity.

\section{References}

BIRD, R. B. - STEWART, W. E. - LIHGTFOOT, E. N. 1960. Transport phenomena. New York : John Wilie \& Sons.

DOMINGUES, J. D. - KIRK, A. D. 2003. Method of preventing discoloration of dough, dough composition and dough products. Patent EP1631149A1.
BOŽIKOVÁ, M. - HLAVÁČ, P. 2010. Selected physical properties of agricultural and food products (scientific monograph). Nitra : SUA. ISBN 978-80-552-0428-4.

FIGURA, L. O. - TEIXEIRA, A. A. 2007. Food physics, physical properties - measurement and applications. USA : Springer. $550 \mathrm{pp}$.

CHIN, N. L. - CAMPBELL, G. M. - THOMPSON, F. 2005. Characterisation of bread doughs with different densities, salt content and water levels using microwave power transmission measurement. In Journal of Food Engineering, vol. 70, pp. 211-217.

KOKSEL, F. - SCANLON, M. G. 2012. Effects of composition on dough development and air entrainment in dough made from gluten-starch blends. In Journal of Cereal Science, vol. 56, pp. 445-50.

MUNSON, B. R. - YOUNG, D. F. - OKIISHI, T. H. 1994. Fundamentals of fluid mechanics. New York : John Wilie \& Sons.

PETROFSKY, K. E. - HOSENEY, R. C. 1995. Rheological properties of dough made with starch and gluten from several cereal sources. In Cereal Chemistry, vol. 72, pp. 53-58.

SAHIN, S. - SUMNU, S. G. 2006. Physical properties of foods. USA : Springer. $257 \mathrm{pp}$.

SHIH, F. F. - TRUONG, V. D. - DAIGLE, K. W. 2006. Physicochemical properties of gluten-free pancakes from rice and sweet potato flours. In Journal of Food Quality, vol. 29, 2006, pp. 97-107.

WATANABE, A. - LARSSON, H. - ELIASSON, A. C. 2002. Effect of physical state of nonpolar lipids on rheology and microstructure of gluten-starch and wheat flour doughs. In Cereal Chemistry, vol. 79, 2002, pp. 203-209.

YANG, Y. - SONG, Y. - ZHENG, Q. 2011. Rheological behaviours of doughs reconstituted from wheat gluten and starch. In Journal of Food Science and Technology, vol. 48, 2011, pp. 489-493.

\section{Contact address:}

Mgr. Peter Hlaváč, PhD., Slovak University of Agriculture in Nitra, Faculty of Engineering, Department of Physics, Tr. Andreja Hlinku 2, 94976 Nitra, Slovak Republic, e-mail: Peter. Hlavac@is.uniag.sk 